\title{
Retraction Note: Spatiotemporal variation of rainfall based on random sample classification and English vocabulary translation of imported products
}

\section{Lili Wang ${ }^{1}$}

Published online: 16 November 2021

(c) Saudi Society for Geosciences 2021

Retraction Note: Arabian Journal of Geosciences (2021) 14: 1524

https://doi.org/10.1007/s12517-021-08003-4

The Editor-in-Chief and the Publisher have retracted this article because the content of this article is nonsensical. The peer review process was not carried out in accordance with the Publisher's peer review policy. The author has not responded to correspondence regarding this retraction.

The original article can be found online at https://doi.org/10.1007/ s12517-021-08003-4.

Lili Wang

wang20200001@126.com

1 Zhengzhou University of Technology, Zhengzhou 450044, Henan, China 